\title{
Infrared Recombination Lasers Pumped by Low Energy Nd:YAG and Excimer Lasers
}

\author{
C. Momma, M. Hube, A. Tünnermann, K. Mossavi, and B. Wellegehausen \\ Universität Hannover, Institut für Quantenoptik, Welfengarten 1, W-3000 Hannover 1, Fed. Rep. Germany
}

Received 30 August 1991/Accepted 31 October 1991

\begin{abstract}
. 24 infrared laser lines on atomic and ionic transitions have been observed in recombining plasmas by vaporizing and ionizing $\mathrm{Cd}, \mathrm{Pb}, \mathrm{Sn}, \mathrm{Zn}$, and $\mathrm{Mg}$ with low energy $\mathrm{Nd}$ : $\mathrm{YAG}$ or excimer pump-lasers. For operation and optimization of the recombination lasers separated plasma spots and a plasma confinement have been used. The operation of shorter wavelength systems by isoelectronic scaling is discussed.
\end{abstract}

PACS: $42.55,42.60 \mathrm{~B}, 52.50 \mathrm{~J}$

By focussing a pulsed laser with a sufficient peak power onto a target surface (intensity $>10^{8} \mathrm{~W} / \mathrm{cm}^{2}$ ), a hot plasma is created which expands rapidly after the laser pulse. During this expansion preferently three body recombination processes occur, leading to the creation of inversions at lower ionization stages within the expanding plasma $[1,2]$.

By this technique, recombination lasers have been realized in a lot of elements at different wavelengths. In 1979, W.T. Silfvast et al. observed the first laser-produced plasma recombination laser (in $\mathrm{Cd}$ [1]) by vaporizing solid target material, and with similar experimental arrangements the same group developed atomic and ionic recombination lasers in many other elements oscillating in the $467 \mathrm{~nm}$ to $2070 \mathrm{~nm}$ spectral range $[3,4]$.

Recombination lasers are scalable to short wavelengths and therefore strong efforts are presently undertaken to obtain with this technique laser oscillation also in the VUV and soft X-ray spectral range. So far gain has been measured in a number of highly ionized elements with the shortest wavelengths of around $5 \mathrm{~nm}[5]$.

While for the short wavelength laser experiments very high power pump-lasers $(\approx 1 \mathrm{TW})$ have been used to produce the necessary plasma conditions [5, 6], recombination lasers in the infrared can be operated at very low pump energies $(\approx 1 \mathrm{~mJ}$ in $10 \mathrm{~ns})$ and with very simple setups [1]. Nevertheless, only a few detailed studies of infrared recombination lasers have been performed up to now $[1,4,7]$.

The operation of these lasers depends mainly on the initial plasma conditions and the expansion and cooling behavior of the plasma. The initial plasma conditions thereby are determined by the pump-laser and target properties. The expansion and cooling behavior and thus the structure and size of the gain medium can be influenced by a background gas, a geometrical guiding technique of the plasma and by the focussing geometry of the pump beam.

So far, experiments have mostly been performed with $\mathrm{CO}_{2}$ lasers for plasma production [1] in combination with multi-spot $[3,4]$ and devices with cylindrical foci [8]. In this contribution we present experiments on the realization and optimization of recombination lasers in atoms and singly charged ions in the near infrared spectral range and studies on the dependence of pump-laser wavelength and pulse duration. Three different pump-lasers have been applied, a $\mathrm{Nd}$ : YAG laser $(1064 \mathrm{~nm}, 10 \mathrm{~ns})$ and for the first time a $\mathrm{KrF}$ excimer laser $(248 \mathrm{~nm}, 20 \mathrm{~ns})$ and also a short $(360 \mathrm{fs})$ pulse $\mathrm{KrF}$ excimer laser system. Basic investigations and comparisions have been performed for the well known atomic Cd recombination laser lines at $1.4 \mu \mathrm{m}$. In addition to many already known systems, 11 new infrared atomic and ionic recombination lasers have been operated. Data and characteristics of these lasers will be presented. The realization of shorter wavelength systems by isoelectronic scaling is discussed.

\section{Experimental}

The experimental setup for the recombination laser experiments is shown in Fig. 1. Three different pump-lasers have been used, a Nd:YAG laser at $1064 \mathrm{~nm}$ with an output energy of up to $700 \mathrm{~mJ}$ and a pulse duration of $10 \mathrm{~ns}$, a $\mathrm{KrF}$ excimer laser at $248 \mathrm{~nm}$ with a maximum output energy of $600 \mathrm{~mJ}$ and a pulse duration of $20 \mathrm{~ns}$, and a short pulse $\mathrm{KrF}$ excimer laser system with an output energy of about $10 \mathrm{~mJ}$ 


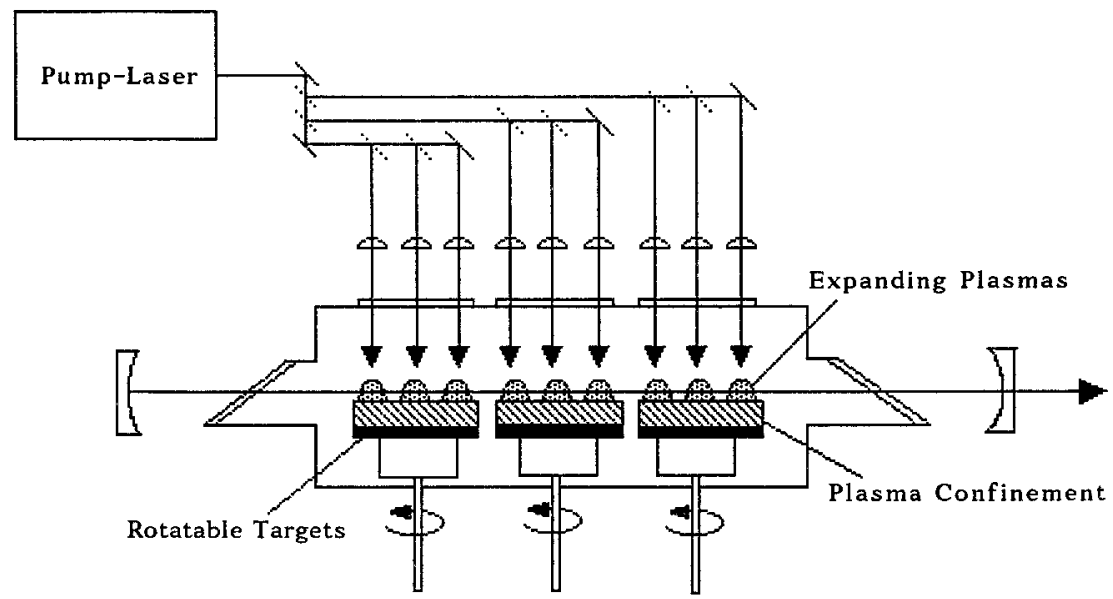

Fig. 1. Experimental setup

at a pulse duration of $360 \mathrm{fs}$. The pump-laser beams were divided by dielectric mirrors in up to 9 beams with equal energy. They were focussed by $f=150 \mathrm{~mm}$ lenses onto three targets, generating three plasma spots at each target with a spot to spot distance of $15 \mathrm{~mm}$ and a spot diameter of about $150 \mu \mathrm{m}$. The targets were rotating during the experiments to avoid the creation of holes on the target surface. In front of each target two horizontal, parallel Al plates with a distance of $3 \mathrm{~mm}$ and a size of $1 \times 10 \times 100 \mathrm{~mm}$ were installed to confine the plasma. The laser beams were focussed onto the targets through the separated plates so that the plasma initially flows through the confinement region before free expansion starts. The expansion is further influenced by $\mathrm{He}$ gas flowing through the cell at a pressure of $1-3 \mathrm{hP}$. The flowing gas also removes evaporated and sputtered particles, so that, in connection with the rotating targets, laser operation of several hours at a repetition rate of $10 \mathrm{~Hz}$ was possible without appreciable change of output intensity.

For the laser experiments linear symmetric resonators ( $R=500 \mathrm{~mm}$ to $2000 \mathrm{~mm}$ ) with low output coupling were used. The resonator axis was adjusted $1-3 \mathrm{~mm}$ in front of the confinement plates and the laser radiation was detected by a Ge diode or a S-1 photomultiplier. For the determination of the laser wavelengths a monochromator (resolution $0.5 \AA$ ) was used.

Lasing action was verified by observing a strong signal enhancement (several orders of magnitude) when an optical resonator was applied and a more than linear increase of laser intensity near laser threshold by rising the amplification length (spot number).

The small signal gain of the recombination lasers was measured by inserting variable losses into the resonator, realized by glass plates tilted against the Brewster-angle.

\section{Results and Discussion}

With the described setup, experiments have been made to vary the properties of the inital plasma, the behavior of the expanding plasma and the geometry of the gain region.

One possibility to optimize the output energy of recombination lasers is given during the creation of the initial plasma. The properties of this plasma are defined by target material and pump-laser radiation. For a given target material and energy level scheme, the pump-laser, in principle, can be varied in wavelength, pulse duration, energy, and beam diameter. Especially the influence of pump-laser wavelength and pulse duration were investigated. For these experiments the $\mathrm{Cd}$ recombination laser with 3 atomic lines around $1.4 \mu \mathrm{m}$ (see Table 2) had been chosen. This laser is easy to operate and has already been investigated in detail, especially with a $\mathrm{CO}_{2}$ laser pump source [1]. Results for $\mathrm{Nd}$ : YAG and $\mathrm{KrF}$ excimer laser pumping are summarized in Table 1.

By comparing the results of the two excimer lasers, only a slight difference in pump energy at laser threshold and in small signal gain of the Cd laser can be seen (Table 1). This means that the processes during plasma production and expansion lead in summary to similar results for both lasers, although, the single processes (plasma creation, plasma heating, plasma expansion etc.) may differ. In addition, a remarkable difference should be mentioned: While for the nspulses the plasma expansion is homogeneous and spherical, in the case of the fs-pulses this expansion is preferentially directed in forward direction (normal to the target surface) and is rather inhomogeneous in direction of the resonator axis as can be seen from the visible radiation of the expanding plasma cloud. This leads to a more difficult alignement
Table 1. Operating conditions of the atomic Cd laser at $1.4 \mu \mathrm{m}$ for different pump-lasers and a single plasma spot

\begin{tabular}{|c|c|c|c|c|c|}
\hline Pump-laser & $\begin{array}{l}\text { Pump-laser } \\
\text { wavelength } \\
{[\mathrm{nm}]}\end{array}$ & $\begin{array}{l}\text { Pump-laser } \\
\text { duration }\end{array}$ & $\begin{array}{l}\text { Pump-laser } \\
\text { energy at } \\
\text { threshold }^{a} \\
{[\mathrm{~mJ}]}\end{array}$ & $\begin{array}{l}\text { Pump-laser } \\
\text { power at } \\
\text { threshold } \\
{[\mathrm{kW}]}\end{array}$ & $\begin{array}{l}\text { Max. gain } \\
\text { coefficient }^{b} \\
{\left[\% \mathrm{~cm}^{-1}\right]}\end{array}$ \\
\hline Excimer & 248 & $20 \mathrm{~ns}$ & 0.7 & 35 & 0.3 \\
\hline Excimer & 248 & $360 \mathrm{fs}$ & 1.1 & $3 \times 10^{6}$ & 0.2 \\
\hline $\mathrm{Nd}: \mathrm{YAG}$ & 1064 & $10 \mathrm{~ns}$ & 0.4 & 40 & 0.3 \\
\hline
\end{tabular}


of the recombination laser and may be one reason for the slightly lower gain of the short pulse pumped $\mathrm{Cd}$ laser.

The comparison between ns-excimer laser and Nd:YAG laser pumping shows no substantial differences in threshold or gain, although, from the theory of laser-induced plasmas, a clear difference in the initial plasma density, defined by the critical electron density $n_{\mathrm{c}}$, can be assumed, due to the different wavelengths $n_{\mathrm{c}} \approx 10^{21} \mathrm{~cm}^{-3}$ for the Nd:YAG laser and $n_{\mathrm{c}} \approx 10^{22} \mathrm{~cm}^{-3}$ for the $\mathrm{KrF}$ excimer laser). However, during the expansion into the gain region a substantial change of the initial plasma conditions occurs and the density is reduced to approximately $10^{13} \mathrm{~cm}^{-3}$ for atomic recombination lasers, so that the initial plasma density plays no important role for this kind of lasers. As calculations show a low density is necessary because otherwise electron quenching processes due to electron-atom collisions destroy a possible population inversion. The inversion densities are in the range from $10^{8}$ to $10^{9} \mathrm{~cm}^{-3}$ for these lasers. From these data maximum output energies in the pJ-range depending on the amplification length can be estimated.

In addition to the initial pump-laser conditions, the plasma can be further influenced during its expansion into the gain region. Here, two parallel metal plates were used, similar to experiments in [9]. This confinement technique leads to a more compact, spatially controlled and elongated inversion zone and an additional cooling mechanism of the plasma. With this technique a strong enhancement of laser output energy was obtained and in some cases (e.g. $\mathrm{Mg}$, $\mathrm{Mg}^{+}$), laser oscillation was only possible by applying this confinement.

Generally, a high gain can be generated by high inversion density or a large gain length. Because the maximum inversion for recombination lasers is limited by (quenching) electron density, larger excitation lengths have to be applied to achieve a higher gain. The use of a confinement increases the length of the inversion zone per plasma spot from approximately $10 \mathrm{~mm}$ without confinement to about $15 \mathrm{~mm}$. However, for much longer excitation zones a line focus [8] or a number of separated spots $[3,4]$ have to be used. To investigate the influence of the excitation geometry, up to nine separated plasma spots were applied. For the studied laser transitions saturation was observed at a certain spot number.

By changing the distance between the plasma spots the line focus situation can also be simulated. Figure 2 shows the output intensity for $\mathrm{ab}$ laser at $1.53 \mu \mathrm{m}$ in dependence of the spot-to-spot distance at the target. It can be clearly seen that separated spots, where no overlapping of the single plasmas occurs, give better results than shorter distances between the spots. This may be explained by an inhibition of the free expansion into the surrounding buffer gas and thus a reduction of the strong cooling for overlapping excitation zones. Separated plasma spots therefore seem to be better suited than a line focus.

Experiments to realize recombination lasers have been carried out in $\mathrm{Cd}, \mathrm{Pb}, \mathrm{Sn}, \mathrm{Zn}$, and $\mathrm{Mg}$. Under optimized conditions the laser lines listed in Table 2 have been observed. The laser lines have been assigned to transitions by measuring the wavelength with a monochromator and comparing them with atomic and ionic transition data [10]. The assignment has been supported by the very different tempo-

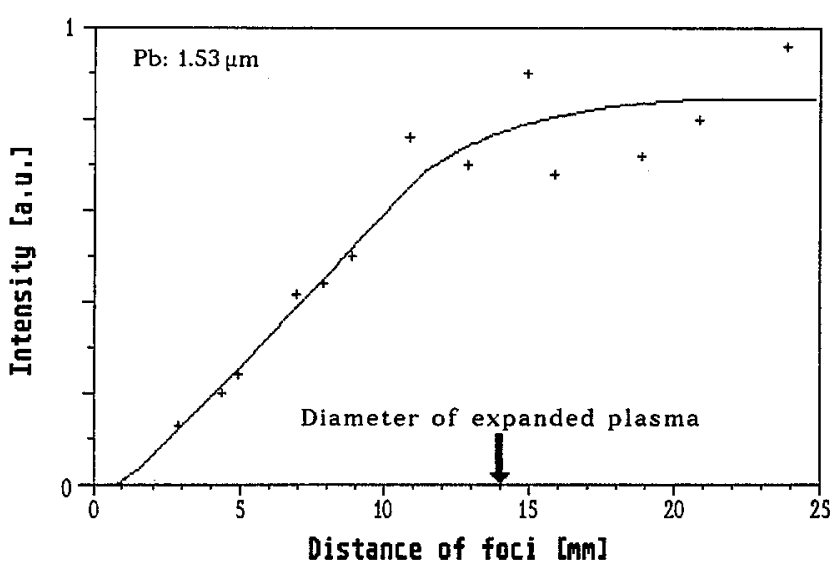

Fig. 2. Intensity of the $\mathrm{Pb}$ laser $\left(1.53 \mu \mathrm{m}, 5 f^{3} F_{2}-6 d^{3} F_{3}^{0}\right)$ in dependence of the distance between two plasma spots $(5 \mathrm{~mJ}$ per plasma spot, without confinement)

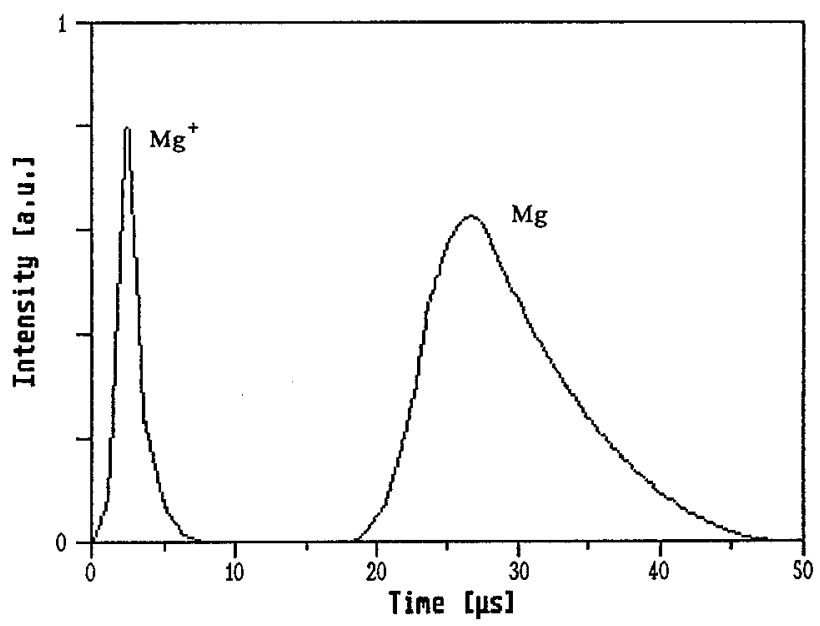

Fig. 3. Temporal behavior of an atomic and an ionic $\mathrm{Mg}$ laser at $1.08 \mu \mathrm{m}\left(5 f^{3} F^{0}-3 d^{3} D\right)$ and $1.09 \mu \mathrm{m}\left(4 p^{2} P_{3 / 2}^{0}-3 d^{2} D_{5 / 2}\right)$ respectively

ral behavior of atomic and ionic laser lines, which is shown in Fig. 3 for $\mathrm{Mg}$ and $\mathrm{Mg}^{+}$. The singly charged ionic laser at $1.08 \mu \mathrm{m}$ starts to oscillate $\approx 1 \mu \mathrm{s}$ after the pump-laser shot with a pulse duration of $1-2 \mu \mathrm{s}$, while the atomic laser at $1.09 \mu \mathrm{m}$ starts after about $10 \mu \mathrm{s}$ with pulse durations of 10 $20 \mu \mathrm{s}$. This behavior is typical for all observed recombination lasers. Lines in Table 2 marked with a $(a)$ have also been observed before with a $\mathrm{CO}_{2}$ pump-laser $[3,4]$ while all other laser lines to our knowledge have been realized for the first time in laser-produced plasmas. Lines marked with a (b) have first been observed with an excimer laser as pump source for plasma production.

The successful operation of many new recombination lasers in atoms and singly charged ions demonstrated here at relatively low pump-laser energies for plasma production gives hope that with moderate power lasers also shorter wavelength recombination lasers may be possible, for example by considering corresponding transitions at higher ionization stages. This isoelectronic scaling has been proposed e.g. for the $4 f-3 d$ transition in $\mathrm{Li}$ at $1870 \mathrm{~mm}$, leading to a potential laser transition at $116 \mathrm{~nm}$ in $C^{3+}[3,11-13]$. We analyzed a scaling possibility starting from the $\mathrm{Mg}^{+} 4 p-3 d$ 
Table 2. Realized recombination lasers with Nd: YAG laser pumping

\begin{tabular}{|c|c|c|}
\hline Element & Wavelength $[\mu \mathrm{m}]$ & Transition assignment \\
\hline \multirow[t]{2}{*}{$\mathrm{Mg}$} & $1.488^{\mathrm{a}, \mathrm{b}}$ & $4 f^{3} F_{2,3,4}^{0}-3 d^{3} D_{2,3,1}$ \\
\hline & $1.081^{\mathrm{b}}$ & $5 f^{3} F_{2,3,4}^{0}-3 d^{3} D_{2,3,1}$ \\
\hline \multirow[t]{3}{*}{$\mathrm{Mg}^{+}$} & $1.092^{\mathrm{a}}$ & $4 p^{2} P_{3 / 2}^{0}-3 d^{2} D_{3 / 2}$ \\
\hline & 0.924 & $4 p^{2} P_{1 / 2}^{0}-4 s^{2} S_{1 / 2}$ \\
\hline & 0.922 & $4 p^{2} P_{3 / 2}^{0}-4 s^{2} S_{1 / 2}$ \\
\hline \multirow[t]{3}{*}{$\mathrm{Zn}$} & $1.647^{\mathrm{a}}$ & $4 f^{3} F_{2,3,4}^{0}-3 d^{3} D$ \\
\hline & $1.315^{\mathrm{a}}$ & $5 p^{3} P_{1}^{0}-5 s^{3} S_{1}$ \\
\hline & 1.170 & $5 f^{3} F^{0}-4 d^{3} D$ \\
\hline \multirow[t]{2}{*}{$\mathrm{Zn}^{+}$} & $1.476^{\mathrm{a}, \mathrm{b}}$ & \\
\hline & $1.104^{\mathrm{b}}$ & \\
\hline \multirow[t]{5}{*}{$\mathrm{Cd}$} & $1.640^{\mathrm{a}, \mathrm{b}}$ & $4 f^{3} F_{2,3,4}^{0}-5 d^{3} D_{1}$ \\
\hline & $1.448^{\mathrm{a}, \mathrm{b}}$ & $6 p^{3} P_{0}^{0}-6 s^{3} S_{1}$ \\
\hline & $1.433^{\mathrm{a}, \mathrm{b}}$ & $6 p^{3} P_{1}^{0}-6 s^{3} S_{1}$ \\
\hline & $1.398^{\mathrm{a}, \mathrm{b}}$ & $6 p^{3} P_{2}^{0}-6 s^{3} S_{1}$ \\
\hline & 1.163 & \\
\hline \multirow[t]{2}{*}{$\mathrm{Cd}^{+}$} & 1.425 & \\
\hline & 1.039 & \\
\hline $\mathrm{Sn}$ & $1.119^{b}$ & $6 p^{1} D_{2}-6 s^{1} P_{1}^{0}$ \\
\hline \multirow[t]{2}{*}{$\mathrm{Sn}^{+}$} & $1.075^{\mathrm{a}, \mathrm{b}}$ & $5 f^{2} F_{7 / 2}^{0}-6 d^{2} D_{5 / 2}$ \\
\hline & $1.061^{\mathrm{b}}$ & $5 f^{2} F_{5 / 2}^{0}-6 d^{2} D_{3 / 2}$ \\
\hline \multirow[t]{3}{*}{$\mathrm{Pb}$} & $1.532^{\mathrm{a}, \mathrm{b}}$ & $5 f^{3} F_{2}-6 p^{3} F_{3}^{0}$ \\
\hline & $1.308^{\mathrm{a}, \mathrm{b}}$ & $7 p^{3} P_{1}-7 s^{3} P_{1}^{8}$ \\
\hline & $1.106^{\mathrm{b}}$ & $6 f^{1} F_{3}-6 d^{3} F_{3}^{0}$ \\
\hline $\mathrm{Pb}^{+}$ & $1.320^{\mathrm{a}, \mathrm{b}}$ & $6 f^{2} F_{7}^{0}-7 d^{2} D_{5 / 2}$ \\
\hline
\end{tabular}

a Also observed in earlier experiments with $\mathrm{CO}_{2}$ pump-lasers [3, 4]

b Also realized with excimer laser pumping a.)

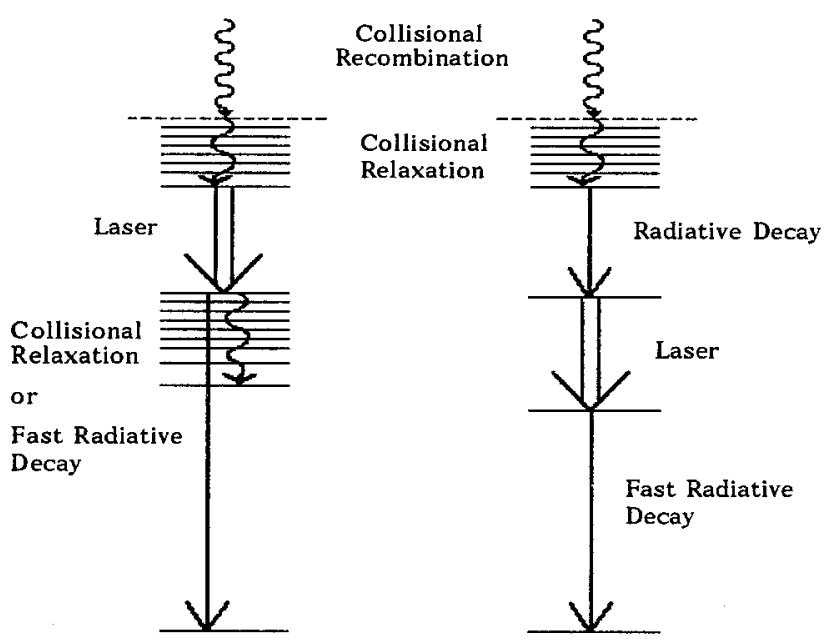

Fig. 4a,b. Schematic energy level scheme for typical infrared recombination lasers $\mathbf{a}$ and for the $\mathrm{Mg}^{+}$system $\mathbf{b}$

laser line at $1.09 \mu \mathrm{m}$. This transition in $\mathrm{Mg}^{+}$is located at relatively low lying energy-levels compared to most infrared recombination lasers, which is shown schematically in Fig. 4. Furthermore, the population and depopulation processes differ, as both, upper and lower laser level, are stronger influenced by spontaneous emission than by electron-atom impacts. The potential advantage of such a system is a smaller branching ratio during the relaxation processes after recombination and thus a higher efficiency for the population of
Table 3. Isoelectronic scaling of the $\mathrm{Mg}^{+}$laser $\left(1.09 \mu \mathrm{m}, 4 p^{2} P-3 d^{2} D\right.$ transition)

\begin{tabular}{|c|c|c|c|}
\hline & $\mathrm{Mg}^{+}$ & $\begin{array}{l}\mathrm{Al}^{2+} \\
\text { (proposed) }\end{array}$ & $\begin{array}{l}\mathrm{Si}^{3+} \\
\text { (proposed) }\end{array}$ \\
\hline$\lambda[\mathrm{nm}]$ & 1092.2 & 360.2 & 172.3 \\
\hline$A_{\mathrm{u}}\left[10^{8} \mathrm{~s}^{-1}\right]$ & 0.3 & 1.3 & 2.8 \\
\hline$A_{1}\left[10^{8} \mathrm{~s}^{-1}\right]$ & 4.0 & 12.2 & 24.2 \\
\hline$\sigma\left[10^{-12} \mathrm{~cm}^{2}\right]$ & $\sim \quad 4.1$ & 0.6 & $\sim 0.1$ \\
\hline $\begin{array}{l}\text { Estimated } \\
\text { pump energy } \\
{[\mathrm{mJ} / \text { focus }]}\end{array}$ & 12 & 22 & 45 \\
\hline
\end{tabular}

$A_{\mathrm{u}}, A_{1}$ : upper, lower level spontaneous transition rates

$\sigma:$ stimulated emission cross section

the upper laser level, and, furthermore, a better possibility to calculate a scaling to higher ionization stages, because spontaneous emission rates do not depend on the electron density and have been measured for a lot of elements. The scaling of the $\mathrm{Mg}^{+} 1.09 \mu \mathrm{m}$ line would lead to $360 \mathrm{~nm}$ in $\mathrm{Al}^{2+}$ and to $172 \mathrm{~nm}$ in $\mathrm{Si}^{3+}$. The relevant data of $\mathrm{Mg}^{+}$, $\mathrm{Al}^{2+}$, and $\mathrm{Si}^{3+}$ are shown in Table 3. Considering the spontaneous transition rates $A_{\mathrm{u}}$ of the upper and $A_{1}$ of the lower levels it should be possible to produce an inversion in a similar way as for $\mathrm{Mg}^{+}$. Unfortunately, the calculated stimulated emission coefficients $\sigma$ for the $4 p-3 d$ transitions are lower by a factor of 7 and 40 , respectively, compared to the $\mathrm{Mg}^{+}$transition, which means that higher inversion densities and larger amplification lengths (more plasma spots) will be necessary. Fortunately, higher inversion densities can be expected automatically by scaling recombination lasers to higher ionization stages and thus shorter wavelengths [14, 15], if appropriate initial plasma conditions can be established.

To determine the necessary pump energy per plasma spot for the considered $\mathrm{Al}^{2+}$ and $\mathrm{Si}^{3+}$ laser, the different ionization stages of the elements in dependence of the laser intensity (Nd:YAG laser: $1064 \mathrm{~nm}, 10 \mathrm{~ns}$; focus size: $150 \mu \mathrm{m}$ ) were calculated by the simplifying assumption of a plasma in local thermal equilibrium during plasma production, because of the short electron thermalization times compared to the pump pulse [16]. Applying the Saha equation and an estimation of the initial plasma temperature in dependence of the laser intensity [17] the estimated pump energies given in Table 3 were obtained. These estimations could be experimentally verified for the $\mathrm{Mg}^{+}$laser (see also Table 3).

\section{Conclusions}

The performed investigations have shown that pump-lasers at different wavelengths and even at very different pulse lengths may be used to realize recombination lasers. For the especially investigated $\mathrm{Cd}$ laser, normal pulse $\mathrm{Nd}$ :YAG and excimer lasers gave comparable thresholds and amplifications, while for a short pulse excimer laser a slightly higher threshold and a smaller gain were observed. For the operation of the lasers it seems to be favorable to use many separated plasma spots with only a low pump energy per plasma spot. In this way a variety of new near infrared atomic and 
ionic recombination lasers has been operated. It appears feasible to realize also shorter wavelength systems with moderate pump energies by isoelectronic scaling of the observed lasers.

\section{References}

1. W.T. Silfvast, L.H. Szeto, O.R. Wood II: Opt. Lett. 4(9), 271 (1979)

2. L.I. Gudzenko, L.A. Shelepin, S.I. Yakulenko: Sov. Phys. Usp. 17(6), 848 (1975)

3. O.R. Wood II, J.J. Macklin, W.T. Silfvast: Appl. Phys. Lett. 44(12), 1123 (1984)

4. O.R. Wood II, J.J. Macklin, W.T. Silfvast: IEEE J. QE-21(10), 1714 (1985)

5. M.H. Key, M. Grande, C. Hooker, S. Rose, I. Ross, M. Shaw, G. Tallents, H. Baldis, D. Brown, P. Norreys, E. Wooding, C. Lewis, M. Lamb, D. O'Neill, C. Regan, P. Fews, G. Pert, S. Ramsden, Y. Kato, M. Yamanaka: Proceedings of 19th European Conference on Laser Interaction with Matter (ECLIM-19), October 3-7, 1988, Madrid, Spain, p. 17

6. Y. Kato, E. Miura, T. Tachi, H. Shiraga, H. Nishimura, H. Daido, M. Yamanaka, T. Jitsumo, M.Takagi, P.R. Herman, H. Takabe,
S. Nakai, C. Yamanaka, M.H. Key, G.J. Tallents, S.J. Rose, P.T. Rumsby: Appl. Phys. B 50, 247 (1990)

7. B. Wernsman, J.J. Rocca, H.L. Mancini, D. Schinca, J.O. Tocho: IEEE J. QE-26(9), 1624 (1990)

8. W.T. Silfvast, L.H. Szeto, O.R. Wood II: Appl. Phys. Lett. 34(3), 213 (1979)

9. W.T. Silfvast, L.H. Szeto, O.R. Wood II: Appl. Phys. Lett. 36(7), 500 (1980)

10. Chemical Rubber Company (eds.): Handbook of Chemistry and Physics, 70th ed. (CRC Press. Boca Raton 1989)

11. W.T. Silfvast, L.H. Szeto, O.R. Wood II: Appl. Phys. Lett. 39(3), 213 (1981)

12. R.U. Datla, J.R. Roberts, W.T. Silfvast, O.R. Wood II: Opt. Lett. 12(9), 675 (1987)

13. T. Hara, K. Ando, H. Yashiro, M. Hamagaki, T. Fusayama, Y. Segawa, Y. Aoyaki, S. Namba: Technical Digest of the XVI Intern'1 Conf. on Quantum Electronics (IQEC), July 18-21, 1988, Tokyo, Japan, p. 514

14. W.L. Bohn: Appl. Phys. Lett. 24(1), 15 (1974)

15. W.T. Silfvast, O.R. Wood II: Opt. Lett. 8(3), 169 (1982)

16. R. Fedosejevs, R. Ottmann, R. Sigel, G. Kühnle, S. Szatmári, F.P. Schäfer: Appl. Phys. B 50, 79 (1990)

17. D. Colombant, G.F. Tonon: J. Appl. Phys. 44(8), 3524 (1973) 